\title{
The Antecedents Intention of Use Mobile Payment for Millennial Generation
}

\author{
Andreas Wijaya*, Lelly Christin, William Andrean Wijaya \\ Universitas Bunda Mulia \\ Jakarta, Indonesia \\ *awijaya@bundamulia.ac.id
}

\begin{abstract}
This research adopting Technology Acceptance Model (TAM) and Mobile payment system characteristics with perceived risk to ensuring and explore the model. The main purpose are determining Mobile payment system characteristics and perceived risk in the TAM model for millennial generation as the subject. Sample was selected through purposive method in order to given closed questionarries in likert scale. As a result are perceived usefulness and perceived ease of use were affected the intention to use mobile payment. The findings in this research had implication and development of mobile payment services, from managerial perspective, the finding in this study can be a consideration to collaboration in stakeholder such as banks, merchant, mobile operators. Future direction to the researcher may well focus on GenX to measuring the intention to use mobile payment.
\end{abstract}

Keywords—mobile payment, TAM, millennial

\section{INTRODUCTION}

The outstanding penetration of smartphone Indonesia have been change the several aspects, the superficial issues is the cashless financial payment. According to [1], the youngster almost using their phones 150 times per day therefore most of businesses change alternative method to make a purchase for goods/services, bill, and invoices with mobile devices and wireless communication technologies in Mobile payment [2]. This structured process had a unique process to value-adding role with the third party to complete the purchase [2]. This technology offered user to conducted payment services with financial institutions, payment service provider, system, and software [3]. Based on [4], in Indonesia, mobile payment was pioneered by the mobile network for a decade ago and followed by other mobile networks, bank, and transportation. In addition, the concept of app based mobile payment was established and change the system of mobile payment. The distinction between each method is apps provides a friendly user interface to consumer [4].

This topic has been raised by several researchers to finding the intention of using Mobile payment using Theory Adaptation Model (TAM) model, such as [5] using mobile payment system characteristics to assess individual intention to use Mobile payment [5]. Other findings from Dahlberg [6] exploring consumer adoption with mobile payment system to knowing perceived of use; Massoth and Bingel [7] seeking mobile payment system characteristics to measure perceived usefulness. Furthermore, Kim et al [8] and Koenig-Lewis [9] measuring consumer intention of use with two viewpoint consumer into perception profit and perception lost.

To explore consumer intention of mobile payment's use. Firstly, this research adopting Technology Acceptance Model (TAM) and Mobile payment system characteristics with perceived risk to ensuring and explore the model research. Furthermore, data were collected via Google docs with the purposive sample to meet the criteria for millennial generation.

\section{LITERATURE REVIEW}

TAM model is currently applied for several researchers to explain IT adoption behavior, with perceived usefulness and perceived ease of use of a system to measure factor user intention [9].

\section{A. Mobile Payment System Characteristics}

System characteristics of mobile payment had a broad category to provide data either for individuals or system everywhere and any time including [9]:

\section{B. Mobility}

Ability to access information with a vary of mobile phone devices and wireless network for anytime and anywhere.

Two main indicators were used measured mobility are independence time and place [10].

- H01a: Mobility won’t be affecting perceived usefulness significantly

- Ha1a: Mobility will be affecting perceived usefulness significantly 
- H0b: Mobility won't be affecting perceived ease of use significantly

- Ha1b: Mobility will be affecting perceived ease of use significantly

\section{Reachability}

Possibility to be touched for anytime, anywhere, and provides] to a particular. Reachable and connected to people and time was used to measured reachability [11].

- H02a: Reachability won’t be affecting perceived usefulness significantly

- Ha2a: Reachability will be affecting perceived usefulness significantly

- H02b: Reachability won't be affecting perceived of use significantly

- Ha2b: Reachability will be affecting perceived ease of use significantly

\section{Compatibility}

Appropriate with the requirement for user situation and give a feasible of new service to fulfillment individual needs. Technology and stay connected were used to measuring compatibility [12].

- H03a: Compatibility won't be affecting perceived usefulness significantly

- Ha3a: Compatibility will be affecting perceived usefulness significantly

- H03b: Compatibility won't be affecting perceived ease of use significantly

- Ha3b: Compatibility will be affecting perceived ease of use significantly

\section{E. Convenience}

Giving uncomplicated to finish a difficultly common task. Anytime, any situation and complexity were used to measured convenience [12].

- H04a: Convenience won't be affecting perceived usefulness significantly

- Ha4a: Convenience will be affecting perceived usefulness significantly

- H04b: Convenience won't be affecting perceived of use significantly

- Ha4b: Convenience will be affecting perceived ease of use significantly

\section{F. Perceived Ease of Use}

Perception of adopting system are simplifying for user in transaction activities and financial issues were used to measure the perceived ease of use [9].

- H05a: Perceived usefulness won't be affecting perceived ease of use significantly

- Ha5a: Perceived usefulness will be affecting perceived ease of use significantly

- H06: Perceived ease of use won't be affecting intention to use significantly

- Ha6: Perceived ease of use use will be affecting intention to use significantly

\section{G. Perceived Usefulness}

Defined as the degree of perception that adopting a system will boost his job performance. Easy to learn and easy to use were used to measure perceived usefulness [9].

- H07: Perceived usefulness won't be affecting intention to use significantly

- Ha7: Perceived usefulness will be affecting the intention to use significantly

\section{H. Perceived Risk}

Perceived risk as defined as negative consequences extent from a user may uncertainties and errors of the internal and external environment while in the process of complete payment using mobile devices [8]. A research framework show in figure 1.

- H08a: Perceived risk won't have moderating effect on perceived usefulness and intention to use

- Ha8a: Perceived risk will have moderating effect on perceived usefulness and intention to use

- H8b: Perceived risk won't have moderating effect on perceived ease of use and intention to use

- Ha8b: Perceived risk will have moderating effect on perceived ease of use and intention to use 


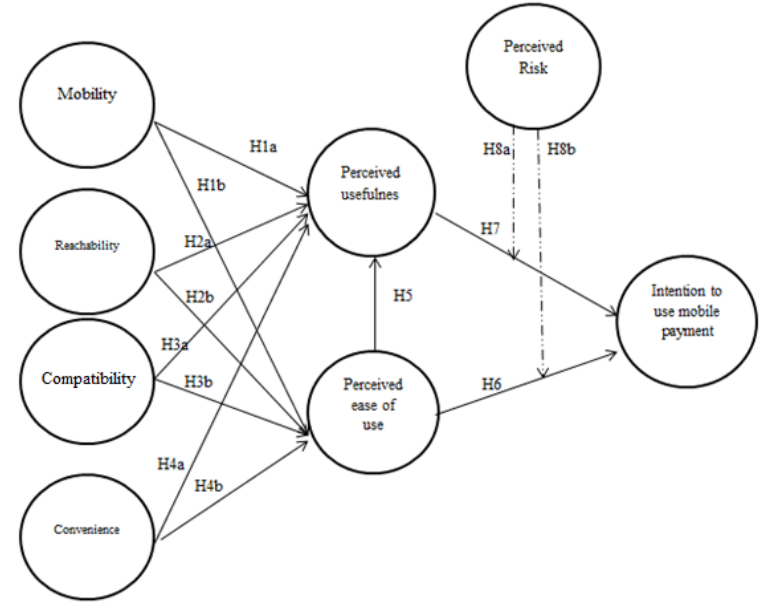

Fig. 1. A research framework.

\section{METHODS}

The data was measured by a structured closed question questionnaire and 5 Likert scale. At the end of period, sample was collected for 428 respondent filtered by purposive sampling which is the selected respondents is the millennial generation.

Data was measured using SMARTPLS03 software, each criteria of indicator reliabilities, convergent and discriminant validity was measured in outer model test), and inner model to investigate the amount of significance of path coefficients test and coefficient of determination test. [13]. Therefore, the amount of AVE (Average Variance Extracted) and reliability was measured by Cronbach's alpha and composite reliability in table 1 below.

TABLE I. CONSTRUCT VALIDITY AND RELIABILITY ANALYSIS

\begin{tabular}{|l|l|l|l|l|}
\hline & $\begin{array}{c}\text { Cronbach's } \\
\text { alpha }\end{array}$ & Rho_A & $\begin{array}{l}\text { Composite } \\
\text { Reliability }\end{array}$ & $\begin{array}{l}\text { Average } \\
\text { Variance }\end{array}$ \\
\hline Mobility & 0.783 & 0.762 & 0.821 & 0.687 \\
\hline Reachability & 0.832 & 0.845 & 0.653 & 0.735 \\
\hline Compatilbility & 0.767 & 0.712 & 0.852 & 0.831 \\
\hline Convenience & 0.921 & 0.918 & 0.783 & 0.751 \\
\hline Perceived usefulness & 0.874 & 0.892 & 0.742 & 0.832 \\
\hline Perceived easy of Use & 0.842 & 0.873 & 8.321 & 0.831 \\
\hline $\begin{array}{l}\text { Intention to use } \\
\text { mobile payment }\end{array}$ & 0.731 & 0.763 & 0.753 & 0.842 \\
\hline
\end{tabular}

Table 1 demonstrates validity and reliability test had exceeded reference thresholds, all items in AVE is highly above 0.5 and Cronbach's alpha, composite reliability 0.70 respectively. Demonstrating the adequate validity of the measurement scales [13].

Looking at the figure 2, it illustrate about coefficient determination test and path coefficient. In addition evaluationg the inner model using endogenous latent variable to assessing path relationships and $\mathrm{R}$ square [13].

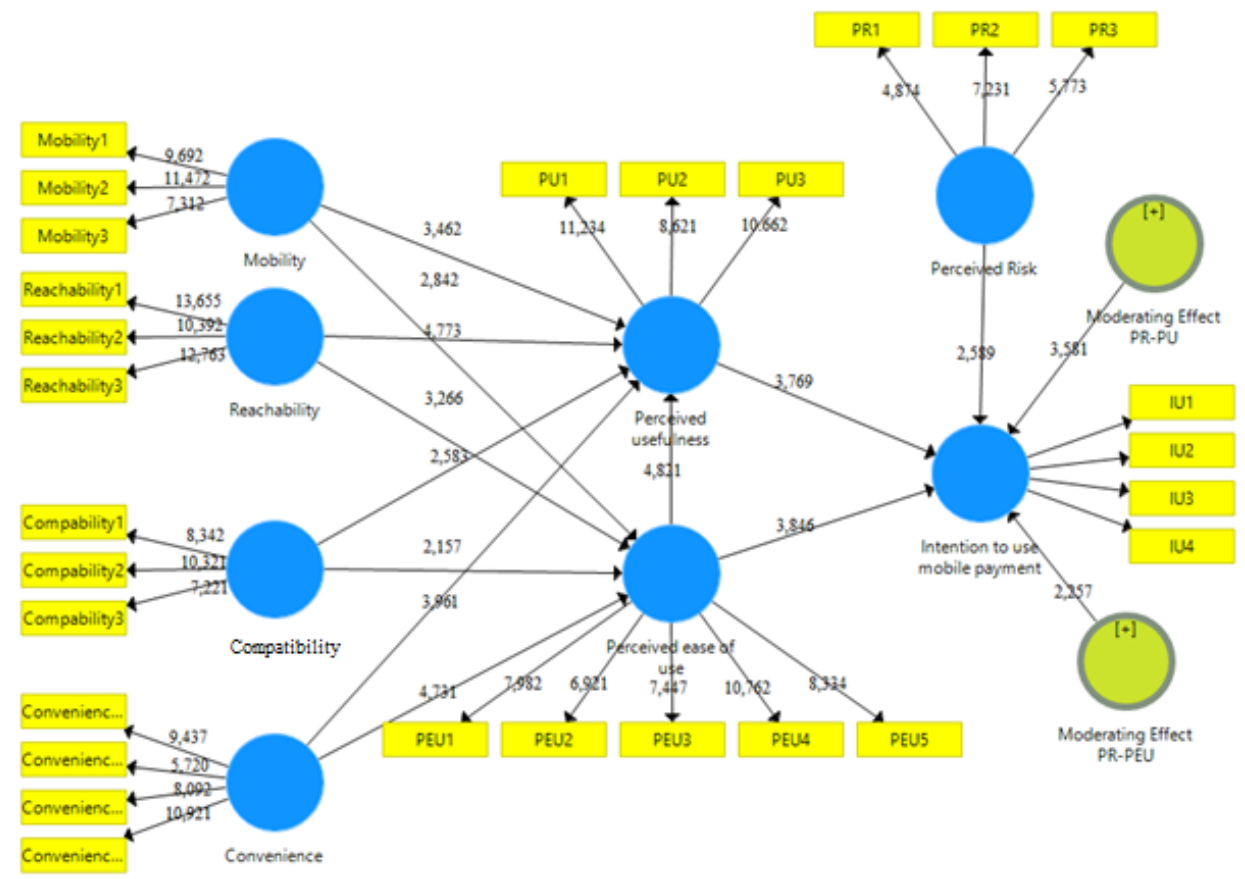

Fig. 2. Full sample analysis result. 


\section{RESULT AND DISCUSSION}

\section{A. Result}

As described in figure 2, mobility, reachability, compatibility, and convenience exceeded rule of thumb $>1,96$ in $\mathrm{T}$ statistics $(\beta 1 \mathrm{a}=3,462, \quad \beta 2 \mathrm{a}=4,733, \quad \beta 3 \mathrm{a}=2,583$, $\beta 4 a=3,961)$, followed by $(\beta 1 b=2,842, \beta 2 b=3,266, \beta 3 b=2,157$, $\beta 4 \mathrm{~b}=4,731)$.

\section{B. Discussion}

Hyphotheses1a-4a and Hyphotheses $1 \mathrm{~b}-4 \mathrm{~b}$ accepted with significant effect. The result mentioned had similarity from $[7,8]$, this finding indicates sense of mobile payment provides mobility, reachability, compatibility, and convenience will be main point to improve perceived usefulness and perceived ease of use. Another variable as perceived ease of use had a significant effect on perceived usefulness and intention to use mobile payment $(\beta 5=4,821),(\beta 6=3,846)$ respectively. Selfsame with [9], identification of this observation lead more improvement in order to preserve more consumer intention to use mobile payment. Therefore, perceived usefulness had a significant effect on the intention to use mobile payment $(\beta 7=3,769)$. Perceived risk can be moderating effect significantly both in perceived usefulness $((\beta 8 \mathrm{a}=3,581)$ and perceived of use $(\beta 8 \mathrm{~b}=2,257)$ to intention to use mobile payment. This findings augment [8] to suggest the providers should to improving security to respond consumer frightened while processing payment. Regarding the explanatory power of in research model, this theoretical model explicates a percent of 61.40 variances in perceived usefulness, a percent of 50.62 variations in perceived ease of use, and a percent of 54.20 variations in intention to use mobile payment

\section{CONCLUSION}

The major purpose on this study was to determine Mobile payment system characteristics and perceived risk in the TAM model to using the mobile payment for millennial generation. Looking at the finding, there are several points to be conclude. Firstly, the mobile payment system characteristics had accepted meet criteria in perceived usefulness to intention to use mobile payment. Furthermore, sample was validated demographics group as input for suggestions in model payment business. The results are perceived usefulness and perceived ease of use were affected the intention to use mobile payment. The findings in this research had implication and development of mobile payment services, from managerial perspective, the finding in this research can be a consideration to collaboration in stakeholder such as banks, merchant, mobile operators. Future direction to the researcher may well focus on GenX to measuring the intention to use mobile payment.

\section{REFERENCES}

[1] J. Brandon, The Surprising Reason Millennials Check Their Phones 150 Times a Day [Online] Retrieved from: https://www.inc.com/johnbrandon/science-says-this-is-the-reason-millennials-check-their-phones150-times-per-day.html. 2017.

[2] T. Dahlberg, J. Guo, and J. Ondrus, "A critical review of mobile payment research," Electron. Commer. Res. Appl., vol. 14, no. 5, pp 265-284, 2015

[3] E.L. Slade, Y.K. Dwivedi, N.C. Piercy, and M.D. Williams, "Modeling consumers' adoption intentions of remote mobile payments in the United Kingdom: extending UTAUT with innovativeness, risk, and trust," Psychol. Mark., vol. 32, no. 8, pp. 860-873, 2015.

[4] MDI ventures "Mobile Payments in Indonesia: Race to Big Data Domination" 2018

[5] S. Laumer and A. Eckhardt, "Why do people reject technologies? towards an understanding of resistance to it-induced organizational change," In ICIS 2010 Proceedings - Thirty First International Conference on Information Systems, 2010.

[6] T. Dahlberg, N. Mallat, J. Ondrus and A. Zmijewska, "Past, present and future of mobile payments research: A literature review," Electronic Commerce Research and Applications, vol. 7, no. (2), pp. 165-181. 2008 .

[7] M. Massoth and T. Bingel, "Performance of different mobile payment service concepts compared with a NFC-based solution," In Proceedings of the 2009 4th International Conference on Internet and Web Applications and Services, ICIW 2009, 2009.

[8] Y. Kim, Y.-J. Park, J. Choi and J. Yeon, "An Empirical Study on the Adoption of "Fintech" Service: Focused on Mobile Payment Services," Advanced Science and Technology Letters, vol. 114, no. (26), pp. 136140,2015

[9] N. Koenig-Lewis, M. Marquet, A. Palmer, and A.L. Zhao, "Enjoyment and social influence: predicting mobile payment adoption. Service Industries Journal, vol. 35, no. (10), 537-554. 2015.

[10] Y.F. Chang, C.S. Chen and H. Zhou, "Smart phone for mobile commerce. Computer Standards and Interfaces. vol. 31, no. (4), pp. 740747. 2009

[11] S. Yang, Y. Lu, S. Gupta, Y. Cao, and R. Zhang, "Mobile payment services adoption across time: An empirical study of the effects of behavioral beliefs, social influences, and personal traits," Computers in Human Behavior, vol. 28, no. (1), pp. 129-142, 2012.

[12] L.D. Chen, "A model of consumer acceptance of mobile payment," International Journal of Mobile Communications, vol. 6, no. 1, pp. 32 52, 2008.

[13] A. Wijaya, Metode Penelitian Menggunakan Smart PLS 03 (1st ed.). Jakarta: Innosains, 2019 